\title{
THE ENVIRONMENTAL ASSESSMENT OF THE INTENSITY OF HEAVY METAL ACCUMULATION IN ANTHROPOGENICALLY TRANSFORMED SOILS
}

\section{Lidia P. Stepanova, Elena V. Yakovleva*, A.V. Pisarev}

\author{
Orel State Agrarian University, Orel, Russia
}

\begin{abstract}
The protection of urban soils and soils located near arterial highways from heavy metal contamination is an environmental issue which has not been resolved in megalopoleis. Purposeful scientific experimental data obtained on the basis of field and laboratory studies is required in order to solve these problems, which has determined the choice of the research objective: to assess the degree of degradation changes in anthropogenically transformed soils in Moscow and Orel regions in terms of total content of heavy metals and their degree of mobility.
\end{abstract}

Keywords: soil certificate, farming system, natural landscape, degradation, soil erosion, agro-technology

\section{Introduction}

The contamination of the environment with toxic substances, including heavy metals, is one of the most serious ecological problems nowadays. The main sources of environmental pollution in industrialized cities are transport and industry. The road traffic complex is one of the most important components of the Russian economy; however, it has a negative impact on urban soils. An integrated approach to the study of all kinds of pollution is essential, as well as taking into account the degree to which various pollution sources influence functioning of natural and anthropogenic landscapes.

\section{Material and methods}

The soil sampling was carried out at six points: three in the area of Kashirskoye Shosse (Highway), as control points (background soils) we used one plot of sod podzolic soil on the territory of the Losiny Ostrov National Park in Moscow and one plot in s. Dumchino in Orel region, where we used gray forest soils, typical of this area, with different levels of exposure to the human activity.

The main sources of soil contamination in a city are industrial enterprises, around which areas of air and soil pollution are formed, as almost all types of industries are characterized by high atmospheric emissions of gases - carbon monoxide, nitrogen dioxide and suspended particulate matter. Also territories adjacent to major transport facilities are heavily polluted.

\section{Results and discussion}

The content of heavy metals in soils of cities and other settlements is higher than in arable soils. The lowest levels of total coefficient of chemical pollution (Zc) for heavy metals are registered in the territory of natural landscapes $(Z c=4)$, in urban areas it is 11.2 (V.I. Savich and others, 2012).

A considerable amount of heavy metals $(\mathrm{Cd}, \mathrm{Cu}, \mathrm{Zn}, \mathrm{Pb})$ comes from vehicles. Water-soluble forms of heavy metals come with rainwater, in solid aerosols heavy metals are in the form of different chemical compounds sulfates of $\mathrm{Zn}, \mathrm{Pb}$, oxides of $\mathrm{Zn}, \mathrm{Pb}, \mathrm{Cd}$, sulfides of $\mathrm{Cu}, \mathrm{Zn}, \mathrm{Pb}, \mathrm{Fe}$.

Heavy metals penetrate soil in the form of water and air migrants, and brought by waste.

To assess the nature of the heavy metal accumulation in urban soils, test sites were laid - plots located at different distances from the pollution source - emissions from vehicles on Kashirskoye Shosse (Highway) in Moscow, with sampling the soil in a layer of $0-20 \mathrm{~cm}$. In the examined samples we measured the total content of heavy metals $\mathrm{Cd}, \mathrm{Cu}, \mathrm{Cr}, \mathrm{Ni}, \mathrm{Pb}, \mathrm{Zn}$ and the amount of their mobile forms (Table 1).

The content of heavy metals in the urban soils, exposed to anthropogenic influence, is higher than in the soils of the background territory. The total content of cadmium near the highway was 1.7 times higher than the content of cadmium in the background soil. The copper content was 2.2 times higher than the amount of copper in the park area. It was established that the total content of almost all the metals under study in the urban soils exceeded their total amount in the background soils, for example, the content of chromium was 4.2 times higher, of zinc -2.2 times, of nickel -1.64 times, and the amount of lead was equal to the total content of lead in the background soil. Since the concentration coefficient reflects the intensity of the contamination, the pollution level of these urban soils is assessed as weak for cadmium, copper, zinc, and as medium for chromium (Table 2).

At a distance of 50 meters from the highway, the natural decrease in total amounts of all the examined heavy metals was registered. The total content of cadmium decreased by $13.04 \%$ compared to the content of cadmium in close proximity to the highway, but it was still 1.43 times higher than the concentration of cadmium in the background soils. The total content of copper decreased by almost $65.5 \%$ compared to the amount of copper in the urban soil near the highway and by $25 \%$ in comparison with the total content of copper in the background soil. The content of chromium, nickel, lead and zinc in comparison with the total amount of these metals in the urban soil near the highway decreased, respectively, by $32.76 \%, 54.07 \%$, $68.69 \%$, and $66.45 \%$. If we compare the total amount of chromium, nickel, lead and zinc to their content in the background soil, it may be noted that the total content of these metals in the urban soil is higher than the amount of the specified heavy metals in the background soil only regarding chromium and nickel by 1.92 times and 1.11 times, respectively. The total content of zinc and lead was 0.32 times and 0.74 times lower than the total amount of these metals in the background soil.

The correlation between the distance from the source of pollution and the total content of heavy metals is inconsistent and ambiguous. It was established that the amount of all the examined heavy metals was higher compared to the background soil, almost by 1.79 times for cadmium, by 2.59 times for copper, by 2.66 times for chromium, by 1.5 times for nickel, by 2.38 times for zinc, and only the total amount of lead was higher than the 
Table 1 The content of heavy metals in urban soils $(0-20 \mathrm{~cm}) \mathrm{in} \mathrm{mg} / \mathrm{kg}$

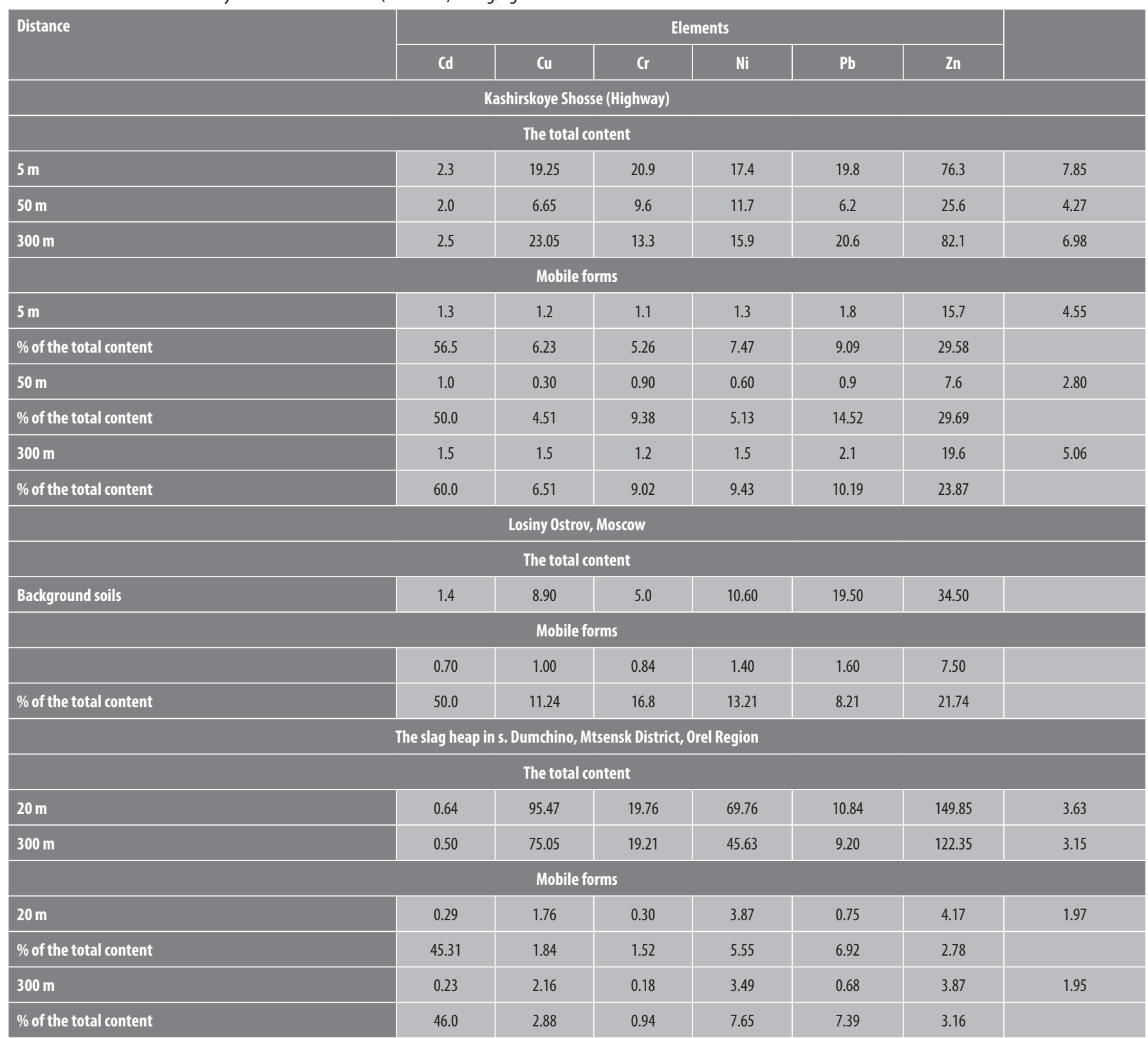

content of this element in the background soil by 1.1 times. However, if we compare the total content of heavy metals in the urban soil in close proximity to the highway and the urban soil at a distance of $300 \mathrm{~m}$ from the highway, it becomes evident that the changes in the heavy metal content do not follow a set pattern. Thus, in the urban soil more distant from the highway there is an increase in total amounts of cadmium by $8.7 \%$, copper by $19.74 \%$, lead by $1.01 \%$, and zinc by $7.6 \%$. The content of nickel, chromium in the urban soil farther away from the highway decreased in comparison with the total content of these metals in the urban soil near the pollution source by $8.62 \%$ and $36.4 \%$, respectively.

The obtained results are confirmed by the total coefficient of pollution; its value dropped to 4.27 in the urban soil at a distance of $50 \mathrm{~m}$ from the highway, and then increased to 6.98 in the urban soil most distant from the highway.

The change in the total content of heavy metals in urban soils located at different distances from the source of pollution - the highway is caused by the peculiarities of pollutant penetration through aeration and vehicle emissions, the state of the soil-absorbing complex, the organic matter content, changes in the $\mathrm{pH}$ of the soil and its grain size distribution, primarily the content of physical clay particles.

In order to give an objective assessment of the influence of traffic on the soil pollution with heavy metals, we conducted research into the accumulation intensity of the total contents of heavy metals and their mobile forms in light gray forest soils at different distances from the slag heap.

The total content of the investigated heavy metals decreased on the test sites located farther away from the slag heap. At a distance of 20 meters from the slag heap the quantitative content of heavy metals in the anthropogenically disturbed soil layer $0-20 \mathrm{~cm}$ changed, for example, the total amount of lead was higher than the amount of this metal in the humus layer of the soil at a distance of 300 meters from the slag heap, by $15.13 \%$. The total content of cadmium in the soils in close proximity to the slag heap increased by $21.88 \%$ compared with its content in the soils located at a greater distance from the heap. The total amount of metals such as copper, zinc and nickel in the soil near the slag heap was higher than the content of these metals in the soil at a distance of $300 \mathrm{~m}$ by 1.3; $1.25 ; 1.53$ times, respectively. The total content of chromium in the test soil 
at a distance of 20 meters and 300 meters from the slag heap was almost the same and varied between $19.76 \mathrm{mg} / \mathrm{kg}$ and $19.21 \mathrm{mg} / \mathrm{kg}$. The value of the total pollution coefficient Zc with heavy metals in the gray forest soils varied from 3.63 at a distance of $20 \mathrm{~m}$ from the slag heap to 3.15 at a distance of $300 \mathrm{~m}$, which characterizes the medium degree of soil contamination.

It is obvious that some toxicants may either increase or weaken the effect of each other on the object under study. In most cases, in actual practice a mixture of substances is to some extent less effective than the sum of the effects of all these substances, and is more effective than any of these substances taken separately.

The influence of heavy metals depends not only on their total content, but primarily, on the amount of water-soluble and mobile forms of heavy metals.

The research has shown that in case of the soil contamination with heavy metals their total content increases in the urban soils (Table 2).

The results presented here clearly demonstrate that the mobility of metals depends not only on the initial total amounts but also on the individual characteristics of these metals and on the properties of the soil environment.

In the urban soils located in close proximity to the highway, the maximum number of mobile forms of heavy metals is registered for cadmium $-56.5 \%$ of the total content, for zinc $-20.58 \%$ and for lead $-9.1 \%$. In comparison with the background soil, the number of mobile forms of these heavy metals increased by 1.86 times for cadmium, by 2.09 times for zinc and by 1.13 times for lead.

The percentage of mobile forms of metals such as chromium, copper and nickel was $5.26 \%, 6.23 \%$ and $7.47 \%$ of the total content of these heavy metals, respectively. The amount of mobile forms of chromium, copper and nickel compared to their content in the background soil increased by 1.31, 13.23 and 0.93 times, respectively.

At a greater distance from the source of pollution $(50 \mathrm{~m})$ the number of mobile forms of heavy metals is sharply reduced in comparison with the content of mobile heavy metals in the urban soils close to the highway.

Thus, the content of mobile cadmium decreased by $23.08 \%$, copper by $75 \%$, zinc - by $51.6 \%$, nickel - by $53.85 \%$, lead - by $50 \%$, chromium - by $18.2 \%$ in comparison with the amount of mobile forms of these metals in the urban soils near the highway.

In comparison with the background soil, the amount of mobile metal increased 1.43 times for cadmium, 1.07 times for chromium and 1.01 times for zinc. The content of mobile forms of copper, nickel and lead decreased compared to the amount of mobile forms of these heavy metals in the background soil, 0.3 and 0.56 times, respectively.

Of interest are the data on the mobility of the metals under study from their original total content in the urban soil located at a distance of $50 \mathrm{~m}$ from the highway. The soil conditions of this research object turned out to be most favourable for the mobility of cadmium - $50.0 \%$ of the total content, zinc $29.69 \%$ and lead $-14.52 \%$; the mobility of zinc, lead and chromium was higher than in the urban soil near the source of pollution, as for copper and nickel, the mobility decreased.

With increasing distance from the source of contamination, as it was established, not only the total content of heavy metals was higher but also the amount of their mobile forms and the degree of the mobility of heavy metals. For example, the amount of mobile cadmium was $60 \%$ of the total content of this element in the urban soil at a distance of $300 \mathrm{~m}$ from the highway, it was higher than the amount of cadmium in the urban soil near the highway by $15.39 \%$ and higher than the amount of cadmium in the urban soil at a distance of $50 \mathrm{~m}$ from the highway by $50 \%$.
The amount of mobile zinc was $23.87 \%$ of the total content in this type of urban soils and the mobility increased by $24.84 \%$ compared to the amount of zinc in the urban soil near the highway. It can be concluded that the properties of the urban soil located farther from the highway were more favourable for the accumulation of the absolute numbers of mobile forms of cadmium, copper, chromium, nickel, lead and zinc, and for the increase in the degree of their mobility. In comparison with the background soil the amount of mobile cadmium increased 2.14 times, of copper - 1.5 times, of chromium -1.43 times, of nickel -1.1 times, of lead -1.31 times and zinc 2.61 times.

The proportion of metals extracted from the sample using the ammonium acetate buffer $\mathrm{pH}=4.8$ decreases for the urban soils near the highway $\mathrm{Zn}>\mathrm{Pb}>\mathrm{Cd}=\mathrm{Ni}>\mathrm{Cu}>\mathrm{Cr}$; for the urban soils at a distance of 50 meters it is $\mathrm{Zn}>\mathrm{Cd}>\mathrm{Cr}=\mathrm{Pb}>\mathrm{Ni}>\mathrm{Cu}$, and for the urban soil at the farthest distance from the highway the proportion of metals decreases in the row $\mathrm{Zn}>\mathrm{Pb}>\mathrm{Cd}=\mathrm{Cu}=\mathrm{Ni}>\mathrm{Cr}$.

The coefficient of the total accumulation of mobile forms of heavy metals in the urban soils was 4.55 in close proximity to the highway, 2.8 at a distance of $50 \mathrm{~m}$ from the highway and 5.06 at the greatest distance from the highway.

The data on the accumulation of mobile forms of heavy metals in the gray forest soils at different distances from the pollution source is also of interest.

The largest amount of mobile forms of the examined metals was found in the layer $0-20 \mathrm{~cm}$ of the gray forest soil at a distance of 20 meters from the slag heap; and in the soil at a distance of 300 meters from the heap a natural decrease in the absolute numbers of mobile metals was observed, the only exception was the data on the contents of mobile copper, its amount increased by $0.34 \mathrm{mg} / \mathrm{kg}$. However, the degree of mobility of the heavy metals under study became higher with increasing distance from the source of contamination. The highest percentage of mobile forms was detected for cadmium $45.31-46.0 \%$, for lead $-6.92-7.39 \%$, nickel $-5.55-7.65 \%$.

In the background soil the highest percentage of mobile forms of heavy metals was registered for cadmium $-50 \%$ of the total content, zinc $-21.74 \%$, chromium - 16.8\%, nickel-13.21, copper - 11.24\%, lead - 8.21.

The proportion of the mobile forms of heavy metals in the gray forest soil decreases in the row $\mathrm{Zn}>\mathrm{Cu}>\mathrm{Ni}>\mathrm{Cr}>\mathrm{Pb}>\mathrm{Cd}$, and in the sod podzolic soil in the row $\mathrm{Zn}>\mathrm{Pb}>\mathrm{Ni}>\mathrm{Cu}>\mathrm{Cr}>\mathrm{Cd}$.

Thus, in case of soil contamination with heavy metals their mobility can both increase and decrease. When the concentration of heavy metals rises to the level of precipitation or the formation of stable complexes, the mobility of heavy metals decreases. However, there may be situations when the concentration of heavy metals in the solution rises and the conditions are created to increase the solubility of the formed precipitation, and the mobility of heavy metals increases.

\section{Conclusions:}

1. The content of heavy metals in the urban soils, exposed to anthropogenic influence, is higher than in the soils of the background territory. The total amount of cadmium near the highway was 1.7 times higher than the total content of cadmium in the background soil. The content of copper was 2.2 times higher than the amount of copper in the park territory. It was established that the total content of almost all the metals under study was higher in the urban soils than in the background soils, for chromium it was 4.2 times higher, for zinc and copper - 2.2, for cadmium 1.7, for nickel 1.64, the content of lead was the same. The level of the 
total contamination is estimated as low for cadmium, copper, zinc, and as medium for chromium.

2. The correlation between the distance from the source of pollution and the total content of the examined heavy metals is not consistent. A higher amount of all the metals under study was detected in the urban soils in comparison with the background soils, for cadmium it was almost 1.79 times higher, for copper -2.59 times, for chromium - 2.66 times, for nickel -1.5 times, for zinc -2.38 times, and only the total content of lead was 1.1 times higher.

3. The change in the total content of heavy metals in the urban soils near the highway and at a distance of $300 \mathrm{~m}$ from the highway is inconsistent. For example, it was established that the total amounts of some metals are higher in the urban soil located farther from the highway, the content of cadmium increased by $8.7 \%$, of copper - by $19.74 \%$, of lead - by $1.01 \%$, of zinc - by $7.6 \%$. The content of nickel and chromium in the soil located farther from the highway decreased in comparison with the total amount of these metals in close proximity to the source of pollution by $8.62 \%$ and $36.4 \%$, respectively.

4. The total content of the examined heavy metals decreased with increasing distance of test sites from the slag heap. At a distance of $20 \mathrm{~m}$ from the heap there was a change in the amount of heavy metals in the anthropogenically disturbed layer of soil $0-20 \mathrm{~cm}$ : the total content of lead was by $15.13 \%$ higher than the amount of this metal in the humus layer of soil at a distance of $300 \mathrm{~m}$ from the heap. The total content of cadmium in the soils located in close proximity to the slag heap increased by $21.88 \%$ in comparison with its amount in the soil located farther. The total content of such metals as copper, zinc, nickel in the soils near the slag heap was 1.3 times, 1.25 times, 1.53 times higher than the content of these metals at a distance of $300 \mathrm{~m}$ from the heap.

5. It was registered that, with increasing distance from the source of contamination, not only the total content of heavy metals increased but also the content of their mobile forms and the degree of heavy metal mobility. For example, the amount of mobile cadmium was $60 \%$ of the total content of this element in the urban soil at a distance of $300 \mathrm{~m}$ from the highway, and it was higher than the content of mobile cadmium in the urban soil near the source of pollution by $15.39 \%$ and higher than the amount of cadmium at a distance of $50 \mathrm{~m}$ from the highway by $50 \%$.

6. The highest content of the mobile forms of the examined heavy metals was detected in the layer $0-20 \mathrm{~cm}$ of the gray forest soil at a distance of 20 meters from the slag heap, as for the soil at a distance of 300 meters from the heap; the natural decrease in the absolute content of mobile metals was registered. However, the degree of mobility of the investigated metals grew with increasing distance from the source of contamination. The highest percentage of mobile forms was detected for cadmium $45.31-46.0 \%$, for lead it was $6.92-7.39 \%$, for nickel it was $5.55-7.65 \%$.

7. The proportion of metals extracted from the sample using ammonium acetate buffer with $\mathrm{pH}=4.8$ decreases for the urban soil near the highway $\mathrm{Zn}>\mathrm{Pb}>\mathrm{Cd}=\mathrm{Ni}>\mathrm{Cu}>\mathrm{Cr}$; for the urban soil at a distance of $50 \mathrm{~m}$ that is $\mathrm{Zn}>\mathrm{Cd}>\mathrm{Cr}=\mathrm{Pb}>\mathrm{Ni}>\mathrm{Cu}$, for the urban soil located farthest from the highway $\mathrm{Zn}>\mathrm{Pb}>\mathrm{Cd}=\mathrm{Cu}=\mathrm{Ni}>\mathrm{Cr}$, and in the background sod podzolic soil $\mathrm{Zn}>\mathrm{Pb}>\mathrm{Ni}>\mathrm{Cu}>\mathrm{Cr}>\mathrm{Cd}$. The proportion of the mobile forms of heavy metals for the gray forest soil decreases in the row $\mathrm{Zn}>$ $\mathrm{Cu}>\mathrm{Ni}>\mathrm{Cr}>\mathrm{Pb}>\mathrm{Cd}$.

\section{References}

SAVICH, V.I. 2001. The Agronomic Evaluation of Humus State of Soils. In Parakhin, N.V. Stepanova, L.V. et al. Orel : Orel State Agrarian University, vol. 1, 2001, 233 p. vol. 2, $204 \mathrm{p}$.

SAVICH, V.I. 2003. The Use of Biological Genetic Tests in the Evaluation of the Contamination of Soil and Agricultural Products with Lead. In Kulikov, A.M. - Vankova, A.A. TSHA Bulletin, vol. 1, 2003, pp. 1-12.

SEDYKH, V.A. 2012. The Change in the Mobility of Heavy Metals in Soils under the Application of High Doses of Organic Fertilizers. Filippov, A.V. - Saidov, A.K. Orenburg State Agrarian University Bulletin, vol. 4, 2012, pp. 209-212.

STEPANOVA, L.P. 2009. The Effect of Aluminum Salt Slag Production Waste on the Ecological State of Gray Forest Soils and Human Health (on the example of the territory of the slag heap MZAL, v. B. Dumchino, Mtsensk district, Oryol oblast. In Yakovleva, E.V. Yashin, A.I. - Myshkin, A.I. Bulletin of PFUR, no. 2, 2009, pp. 82-88.

STEPANOVA, L.P. 2010. The Influence of Technogenesis on the Ecological State of Gray Forest Soils. In Yakovleva, E.V. - Yashin, A.I. Bulletin of PFUR, 2010, no. 2, pp. 50-59.

STEPANOVA, L.P. 2010. The Influence of Technogenesis on the Ecological State of Gray Forest Soils. In Yakovleva, E.V. - Yashin, A.I. Bulletin of PFUR. Series: Ecology and Safety of Living, 2010, no. 2, pp. 27-34.

STEPANOVA, L.P. 2013. The Influence of Technogenesis on the Qualitative Composition and The Quantitative Parameters of Geochemical Anomalies in the Waters of the Oka River. In Yakovleva, E.V. - Korenkova, E.A. - Myshkin, A.I. - Stepanova, E.I. - Tarakin, A.V. Electronic scientific and production journal "AgroEcolnfo", 2013, no. 2 (13).

STEPANOVA, L.P. 2014. The Environmental Assessment of the Organic Fertilizer Effluent Impact on the Chemical and Sanitary-hygienic Indicators of Surface waters and groundwater of Oryol region. In Yakovleva, E. - Cherniy, E. - Korenkova, E. Stepanova, I. - Timonina, A. - Tarakin, A.M. - Pisareva, A. - Tsiganok, E. International Agricultural Journal, 2014, no. 4, pp. 45-48.

YAKOVLEVA, E.V. 2014. The State of Water bodies in the Places of Water Use of the Population of Oryol Region and Measures to Improve the Quality of Drinking Water. In Stepanova, L.P. - Cherniy, E.S. - Korenkova, E.A. - Pisarev, A.V - Myshkin, A.I. The Ecology and the Industry of Russia, 2014, no. 2, pp. 40-45.

Stepanova, L.P. 2015. Agroeconomic assessment of fertility restoration of anthropogenically disturbed and rekultiviruemyh gray forest soils. In Stepanov, L.P. - Yakovleva, E.V. Korenkova, E.A. - Pisareva, A.V. Scientific notes of Oryol State University, 2015, no. 3.

STEPANOVA, L.P. 2015. Ecological and economic evaluation of loss of fertility gray forest soils anthropogenically altered land. In Yakovleva, E.V. - Stepanova, L.P. Science, education and manufacturing, 2015.

YAKOVLEVA, E.V. Fertility Status of anthropogenically - modified with L-soil and its economic evaluation. In Yakovleva, E.V. - Stepanova, L.P. - Korenkova, E.A. Pisareva, A.V. Herald RUDN series Ecology and Life, 2015.

\section{Contact address}

Elena V. Yakovleva, Ph.D. in Agriculture, assistant professor of Orel SAU, 302019. Russia, Orel, General Rodin Str., 69, 疋: +7 962480 9115, e-mail: elenavalerevna79@yandex.ru 